\title{
A Representação Social do Professor da Educação Básica Instituída nas \\ Diretrizes Curriculares do Estado do Paraná
}

\author{
The Social Role of the Teacher from the Basic Education \\ Established in the Curricular Guidelines in the State of Paraná
}

\section{Marilúcia dos Santos Domingos STRIQUER* Elvira Lopes NASCIMENTO**}

Resumo: Neste artigo, apresentamos os resultados da análise da Diretriz Curricular Estadual de Língua Portuguesa, documento oficial orientador das práticas pedagógicas dos professores da rede estadual de ensino do estado do Paraná. Os objetivos foram: identificar quem são os envolvidos no sistema de ensino colocados em cena pela diretriz-e identificar qual a representação social do professor instituída por esse documento. Para tanto, a pesquisa ancorou-se nos pressupostos teórico-metodológicos do Interacionismo Sociodiscursivo (BRONCKART, 2006, 2008, 2009). Os resultados revelam que os principais actantes colocados em cena pelo documento são os professores e os alunos da Educação Básica, e que o professor, em oposição à definição de sujeito epistêmico apresentada pelo documento, é instituído como agente de seu agir.

Palavras-chave: Formação de professores. Figuras do agir. Diretrizes curriculares.

Abstract: On this article, we present the results of the analysis of the State Curricular Guideline in the Portuguese Language, guiding official document

${ }^{1}$ Doutoranda do Programa de Pós-Graduação em Estudos da Linguagem da Universidade Estadual de Londrina (UEL). Professora do Centro de Letras, Comunicação e Artes da Universidade Estadual do Norte do Paraná (UENP), campus Jacarezinho-PR. Contato: marilucia.ss@uol.com.br.

${ }^{2}$ Docente Associada da Universidade Estadual de Londrina. Contato: elopes@sercomtel.com.br. 
of the pedagogical practices of the teachers from the state education system in the state of Paraná. The objectives were: to identify who the people involved in the education system exposed by the guideline are, and identify which the social role of the teacher established by this document is. Therefore, the survey had as a foundation the theoretical-methodological presuppositions from the Socio-discursive Interactionism (BRONCKART, 2006, 2008, 2009). The results reveal that the main actants exposed by the document are the teachers and the students from the Basic Education, and that the teacher, in opposition to the definition of epistemic subject shown by the document, is established as an agent of his action.

Key-words: Teacher's education. Figures of the action. Curricular guidelines.

\section{Introdução}

A Diretriz Curricular Estadual de Língua Portuguesa (DCE-LP) é o documento oficial orientador das práticas pedagógicas dos professores de Língua Portuguesa da Educação Básica do estado do Paraná. Como um texto prescritivo, produzido por instância externa (MACHADO et al., 2009), estabelece além de procedimentos, regras e normas para o trabalho, representações sociais a respeito dos envolvidos na prescrição. E são essas representações sociais e o que é ao trabalhador prescrito o que influenciam, pelo menos inicialmente e/ou em parte, o agir docente (AMIGUES, 2004). Nesse sentido, interessadas em compreender qual a representação que a DCE-LP, isto é, que as instâncias responsáveis pelo sistema educacional do estado têm do professor que age na educação básica no Paraná, nos propusemos a analisar toda a rede discursiva estabelecida nesse documento.

Assim, a análise que apresentamos neste artigo articula dois objetivos: identificar quem são os envolvidos no sistema de ensino colocados em cena pela DCE-LP; e principalmente identificar qual a representação social do professor instituída por esse documento, ou seja, ao professor é atribuído um papel de ator responsável por seu agir ou ele é agente, simples participante de um processo sobre o qual não lhe são atribuídas responsabilidades. A delimitação desses objetivos teve como principal motivação a apresentação da definição de professor pela DCE-LP: o professor é um "sujeito epistêmico" (PARANÁ, 2009, p. 7), concepção que compreendemos à luz de Vygotsky $(2000,2007)$ como o sujeito que se constitui por sua própria 
ação, que age sobre o meio o transformando a fim de satisfazer suas necessidades e desejos, e que é autônomo na construção de seus conhecimentos.

Para alcançar os objetivos, a pesquisa se ancora nos pressupostos teóricos-metodológicos do Interacionismo Sociodiscursivo (ISD) (BRONCKART, 2006, 2008, 2009), para quem o agir e o desenvolvimento daquele que age com a linguagem devem ser estudados por meio dos textosdiscursos, pois estes representam e significam o agir, ou seja, os textosdiscursos são a materialização da ação humana. Nas palavras de Bronckart (2006, p. 139) um texto é "o correspondente empírico/linguístico de uma determinada ação de linguagem", por isso é por meio da rede discursiva instaurada na DCE-LP que as representações sociais podem ser analisadas. Assim, analisamos os textos-discursos produzidos por aqueles que prescrevem o trabalho do professor, buscando desvendar "algumas das representações sociais que se constroem - nessas produções textuais - sobre o trabalhador envolvido na situação de trabalho" (ABREU-TARDELLI, 2006, p. 170).

\section{Fundamentação Teórica}

Para o ISD o principal instrumento semiótico a gerar desenvolvimento no ser humano é a linguagem, por isso é por meio da linguagem (dos textos-discursos) que se interpretam as condutas ativas ou o agir dos agentes produtores das práticas linguageiras situadas. A premissa, formada a partir dos trabalhos de Ricoeur (1983, 1984, 1985)', é a de que "o agir humano não é acessível pela simples observação das condutas humanas observáveis, fornecidas pelos actantes (aquele que age). O agir só existe nos processos interpretativos, daí a necessidade de analisá-lo a partir dos textos que o comentam" (LOUSADA, 2011, p. 63).

Em decorrência, o ISD estabelece algumas definições ad hoc para alguns termos, entre eles os termos ator e agente. Aquele que age, após interpretação de seu agir, pode ser configurado como o responsável por seu agir, por assumir razões e intenções internas (pessoais, singulares), e por

${ }^{1}$ RICOEUR, P. Temps et récit. Paris: Seul.1983, 1984, 1985. v. 1-3, apud MACHADO; BRONCKART, 2009). 
isso recebe a denominação de "ator". Mas, se aquele que age não se configura como responsável por seu agir, se as razões e as intenções que conduziram seu agir foram apenas de caráter coletivo, o termo é "agente" (BALTAR, 2008; MACHADO; BRONCKART, 2009).

E para ser possível interpretar as condutas ativas ou o agir, ou seja, interpretar os papéis de ator ou de agente que assumem os actantes, Bronckart (2009 [1999]), Bronckart e Machado (2004) e Machado e Bronckart $(2005,2009)$ elaboraram um conjunto de procedimentos que constituem o método de análise de textos produzidos em situação de trabalho, sobre o trabalho e prescritivos do trabalho. O método, de agora em diante denominado modelo de análise de texto do ISD, sugere que, primeiro, seja realizado um levantamento do contexto de produção do texto e, depois, dos elementos que compõem o seu "folhado textual" constituído pelos níveis organizacional, enunciativo e semântico.

No nível organizacional, as análises englobam a identificação do plano global do texto, dos tipos de discursos predominantes e dos tipos de sequência. O plano global do texto diz respeito à organização do conteúdo temático mobilizado, podendo ser reconhecido no processo de leitura do texto (BRONCKART, 2009 [1999]). A análise do plano global no âmbito de nossa pesquisa é de suma importância, pois ela "pode nos permitir uma primeira identificação dos tipos principais de agir que são organizados por esse plano, ou de fases da tarefa tematizada ou ainda dos actantes principais postos em cena pelo texto" (MACHADO; BRONCKART, 2009, p. 55). Os tipos de discurso relacionam-se aos mundos representados pelo agente de produção do texto, mundo ordinário (objetivo, social e subjetivo) - e mundos discursivos construídos pelo agir linguageiro (HABERMAS, 1987). Os mundos discursivos são constituídos por meio de dois tipos de operações psicolinguageiras. O primeiro tipo refere-se à relação entre as coordenadas que organizam o conteúdo temático e as coordenadas do mundo ordinário da ação de linguagem. O segundo tipo de operação refere-se à relação entre as instâncias de agentividade, o agente produtor e a situação de produção do texto (BRONCKART, 2006; 2008). A partir do cruzamento dos resultados dessas operações, Bronckart (2009 [1999]) chega a quatro mundos discursivos: narrar implicado, narrar autônomo, expor implicado, expor autônomo. A partir da análise das unidades linguísticas e dos modos de organização sintática que traduzem ou exprimem esses mundos, o autor propõe quatro tipos de discurso: discurso interativo, discurso teórico, relato 
interativo e narração. As sequências referem-se aos modos de planificação dos textos, ou seja, a organização sequencial ou linear do conteúdo temático no texto, sendo elas: narrativa, descritiva, argumentativa, explicativa, injuntiva e dialogal. O nível organizacional prevê ainda a análise dos mecanismos de textualização para a identificação das unidades linguísticas que asseguram a conexão, a coesão nominal e coesão verbal do texto. Segundo Machado e Bronckart (2009), sua análise é fundamental para a identificação dos principais actantes evidenciados pelo texto e das representações construídas sobre eles.

No nível enunciativo as análises são voltadas para a verificação dos mecanismos de responsabilização enunciativa, englobando as marcas de pessoa, marcas de inserção de vozes, ocorrência ou não de modalização, modalizadores subjetivos e adjetivos. No que se refere às marcas de pessoas Machado e Bronckart (2009, p. 59) consideram que "os índices de pessoa parecem ser extremamente útil, no sentido de que ela permite mostrar a manutenção ou a transformação desses valores na progressão textual ou, em outras palavras, como o texto representa o enunciador no agir representado". As vozes podem ser expressas de forma direta - vozes diretas - presentes nos discursos interativos dialogados organizados em turnos de fala, ou de forma indireta podendo ser inferidas em qualquer tipo de discurso - vozes indiretas. Quando em um texto é possível identificar várias vozes do mesmo estatuto ou de estatuto diferente, trata-se de um texto polifônico. As modalizações são as unidades linguísticas que expressam as avaliações julgamentos sobre o conteúdo temático. Bronckart (2009 [1999]) com base nos três mundos de Habermas (1987) (mundo objetivo, mundo social de mundo subjetivo) propõe quatro funções de modalizações: lógica, deôntica, apreciativa e pragmática.

No nível semântico ou nível referente à semiologia/semântica do agir, Bronckart e Machado (2004) propõem que os resultados de análise sejam reinterpretados segundo os conceitos/elementos de uma semiologia do agir (BRONCKART, 2006). As análises no nível semântico são pertencentes a um nível mais micro, voltadas a responder questões relacionadas ao trabalho docente. Essas análises enfocam as escolhas semânticas que aparecem em um texto, bem como a frequência de uso de determinados sintagmas (verbos, substantivos, adjetivos ou advérbios), que configuram um agir linguageiro ou não linguageiro (BULEA, 2010).

O modelo de análise de texto proposto pelo ISD pode ser assim sintetizado: 


\begin{tabular}{|c|c|}
\hline Contexto de produção & Folhado textual \\
\hline $\begin{array}{l}\text { Parâmetros do mundo físico: } \\
\text { - emissor, receptor, espaço e } \\
\text { momento em que o texto é } \\
\text { produzido; } \\
\text { Parâmetros do mundo social e } \\
\text { subjetivo: } \\
\text { - elementos da interação } \\
\text { comunicativa que integram } \\
\text { valores, normas e regras e a } \\
\text { imagem que o emissor tem de si } \\
\text { ao interagir e de seus receptores. } \\
\text { Mais especificamente sobre } \\
\text { textos prescritivos, identificar: } \\
\text { - o(s) gênero(s) mobilizado(s); } \\
\text { - a organização interna global do } \\
\text { texto; } \\
\text { - a fonte da prescrição; } \\
\text { - os destinatários da prescrição; } \\
\text { - textos se articulam ou } \\
\text { respondem. }\end{array}$ & $\begin{array}{l}\text { a) Nível organizacional - análise da } \\
\text { organização temática. Compreende } \\
\text { a identificação do plano global do } \\
\text { texto, do tipo de discurso } \\
\text { predominante, dos tipos de } \\
\text { sequências e dos mecanismos de } \\
\text { textualização (coesão e conexão). } \\
\text { b) Nível enunciativo - envolve os } \\
\text { mecanismos de responsabilização } \\
\text { enunciativa, em geral marcados por } \\
\text { unidades linguísticas, como: a) a } \\
\text { ausência ou a presença de marcas } \\
\text { de pessoa; b) marcas de inserção de } \\
\text { vozes; c) modalizadores; d) } \\
\text { adjetivos. } \\
\text { c) Nível semântico - centra-se nas } \\
\text { escolhas semânticas que aparecem } \\
\text { em um texto, na frequência de uso } \\
\text { de determinados sintagmas (verbos, } \\
\text { substantivos, adjetivos ou } \\
\text { advérbios) que configuram um agir } \\
\text { buscando verificar se o actante do } \\
\text { texto é dotado de razões, intenções } \\
\text { e capacidades para agir. }\end{array}$ \\
\hline
\end{tabular}

Para o alcance dos objetivos a que nos propomos, apenas algumas dessas categorias de análise foram utilizadas.

\section{A Diretriz Curricular Estadual de Língua Portuguesa}

\subsection{O contexto sociointeracional de produção}

O contexto sócio-histórico mais amplo que envolve a produção da DCE-LP se refere à orientação pelo governo do estado de uma reconfiguração dos propósitos da educação paranaense, pautados, sobretudo, 
em um posicionamento divergente aos propósitos político-educacionais dos PCNs e na "reconstrução da identidade educacional paranaense" (SOUZA, 2010, p. 31), na transformação e não mais na adaptação às exigências do mundo do trabalho presentes dos PCNs. Trata-se de uma "suposta retomada dos princípios da educação progressista, principalmente da teoria Histórico-Crítica (SAVIANI, 1984), cujas proposições já haviam embasado os documentos oficiais da educação pública no período de 1986 a 1994" (SOUZA, 2010, p. 12).

Nessa perspectiva, elaborou-se o Plano Estadual de Educação (PEE) para estabelecimento de orientações para todos os níveis e modalidades de ensino. A proposta foi a de construir para cada uma das modalidades de ensino e nível diretrizes curriculares. Logo, no ano de 2004, representantes dos Núcleos Regionais de Educação, da Secretaria de Estado da Educação e representantes dos professores das disciplinas de base comum do Ensino Fundamental foram convidados a formar um grupo permanente para reflexão, discussão e elaboração de proposta que culminassem na construção de novas diretrizes. O grupo também teve o papel de disseminar os debates já realizados e promover, através de encontros descentralizados, o envolvimento dos demais professores.

As discussões realizadas nos seminários e encontros descentralizados serviram de norte para a construção das versões preliminares das DCEs: uma primeira versão em 2005, depois outras em 2006 e 2008. Todas essas versões foram enviadas para as escolas para novas sugestões, alterações e ampliações. Segundo explicita a carta da chefe do Departamento de Educação Básica (DEB), que abre a DCE-LP em sua versão definitiva (PARANÁ, 2009), durante os anos de 2007 e 2008, a equipe pedagógica do DEB percorreu os trinta e dois Núcleos Regionais de Ensino do estado do Paraná (NREs) realizando o evento chamado DEB Itinerante com o objetivo de que os professores pudessem discutir, mais uma vez, "os fundamentos teóricos das DCE quanto aos aspectos metodológicos de sua implementação em sala de aula" (PARANÁ, 2009, p. 9). No ano de 2009 foi publicada a versão final das DCEs.

Esses sujeitos, todos envolvidos na elaboração do documento são, portanto, os seus agentes-produtores; por isso, logo na capa da DCE instaura-se como produtora do documento a SEED e, na folha de rosto estão catalografados os demais envolvidos no processo de produção, a saber: o Governador do Estado, a Secretária de Educação do Estado, o 
Diretor Geral, o Superintendente da Educação, a Chefe do DEB, a Coordenadora das DCEs, a Equipe Técnico Pedagógica da disciplina de Língua Portuguesa, os Leitores Críticos da disciplina de Língua Portuguesa e os Leitores Críticos da Área Pedagógica Educacional. Dessa forma, o caráter oficial e institucional do documento é atenuado. Assim, os produtores são as autoridades institucionais em parceria com os leitores críticos e com os professores participantes das discussões. Mas, o produtor principal é a SEED.

Quanto aos destinatários, a carta da chefe do DEB, que abre a DCE-LP, inicia-se com o enunciado: "Você está recebendo, neste caderno, um texto sobre concepção de currículo para a Educação Básica e as Diretrizes Curriculares Estaduais (DCE) de sua disciplina" (PARANÁ, 2009, p. 7). O pronome "você" refere-se a todos os profissionais da educação do estado do Paraná: professores da Educação Básica, do Ensino Superior e os da formação continuada, coordenadores de área, pedagogos, diretores, integrantes dos Núcleos Regionais de ensino, enfim, todos os envolvidos diretamente com o ensino da língua materna que atuam como profissionais da educação no estado do Paraná são os destinatários do documento. Essa pluralidade pode ser confirmada pela própria expressão utilizada pelo documento: "O que precisa ficar muito claro para os interlocutores deste documento é [...]” (PARANÁ, 2009, p. 54 - grifo das pesquisadoras).

Já os destinatários da prescrição são, mais diretamente, os professores da educação básica. O grau de explicitação desse destinatário está marcado pelo uso de trinta e sete ocorrências diretas a esses professores, sendo que trinta e cinco delas faz uso da expressão professor, uma se dirige ao docente e uma ao educador. Exemplos dos recursos linguísticos empregados para a interação com o destinatário da prescrição: “O professor de Língua Portuguesa precisa, então, propiciar ao educando a prática, a discussão, a leitura de textos das diferentes esferas sociais (p. 51); "Ao trabalhar com o tema do gênero selecionado, o professor propiciará ao aluno a análise crítica do conteúdo do texto e seu valor ideológico" (p. 65).

Portanto, os elementos que compõem o contexto de produção da DCE já apontam que os principais actantes postos em cena pelo documento são: os agentes-produtores do documento e os seus destinatários, sendo que os principais seriam, respectivamente, a SEED e os professores da EB. $\mathrm{Na}$ sequência, analisamos quais são as representações sociais instituídas a eles na construção da textualidade do documento. Para tanto, primeiramente, apresentamos a estrutura formal do texto/documento. 
A presença dos produtores e do destinatário ou, sobretudo, a relação de interação que se estabelece entre eles é evidenciada na identificação dos tipos de discurso empregados: por existir conjunção entre o tema tratado e o mundo de seus agentes produtores, a SEED, que é a responsável pela organização do sistema educacional do estado e agente-produtora do documento, o texto é organizado empregando-se predominantemente o discurso interativo nas cartas, onde estão presentes recursos que remetem aos agentes da interação, com o uso de:

- Verbos na primeira pessoa do plural que evidenciam a participação de quem fala no discurso. Exemplos: "Quando assumimos a gestão governamental...” (PARANÁ, 2009, p. 7).

- Verbos no presente e no pretérito perfeito que marcam o caráter conjunto implicado do mundo discursivo. Exemplos: "apresentam"; "promoveu"; "percorreu"; "passaram" (p. 8-9).

- Pronomes que esclarecem com quem se fala. Exemplos: "Você está recebendo, neste caderno, um texto sobre concepção de currículo para a Educação Básica e as Diretrizes Curriculares Estaduais (DCE) de sua disciplina” (p. 8).

- Dêiticos temporais que marcam o momento da interação. Exemplo: "Esses textos são frutos de um longo processo de discussão coletiva, ocorrido entre 2004 e 2008, que envolveu os professores da Rede Estadual de Ensino e, agora, se apresentam como fundamento para o trabalho pedagógico na escola" (p. 8).

Na seção "1. Dimensão histórica do ensino da língua portuguesa", o discurso predominante é o relato interativo. Nos primeiros parágrafos, os introdutórios, estão presentes pronomes e verbos de primeira pessoa, marcando a interação do agente produtor com os destinatários de forma direta. Exemplo: "O Estado de Direito garante a todos os cidadãos a igualdade perante as leis, porém sabemos que, historicamente, em nosso país, há um descompasso..." (PARANÁ, 2009, p. 38). Mas, no restante do texto, predominam relatos em que o agente-produtor narra o que ocorreu por meio de tempos verbais do pretérito perfeito e do imperfeito como se pode observar nos exemplos: "resultou"; "passou"; "tornou”; "era"; "estavam"; "reproduzia"; "revelava"; "organizava-se"; "visava”; "tinham”; "priorizaram” (p. 38-48), marcando a narração da história da disciplina de Língua Portuguesa através dos tempos. Em todo o texto dessa primeira seção é possível identificar: 
- Organizadores temporais (advérbios, sintagmas preposicionais, coordenativos, subordinativos, etc.), que compõem a disjunção do mundo discursivo, pois este é situado em um tempo e espaço que não tem relação com o mundo do agente-produtor. Exemplo: "No período colonial, a língua mais utilizada pela população era..." (p. 40).

- Anáforas pronominais e de anáforas nominais características do relato interativo. Exemplos: "Historicamente, o processo de ensino de Língua Portuguesa no Brasil, iniciou-se com a educação jesuítica. Essa educação era [...]. O sistema jesuítico de ensino organizava-se, então, ..." (p. 39).

Quanto ao tipo de discurso das seções "2. Fundamentação teóricometodológicos", "3. Conteúdo Estruturante”, "4. Encaminhamento metodológico" e "5. Avaliação: o discurso interativo e o discurso teórico" estão "fusionados, constituindo assim um verdadeiro tipo misto interativo-teórico" (BRONCKART, 2009, p. 192), caracterizados pela presença simultânea de recursos de um e do outro discurso:

i) do domínio do discurso interativo:

- Pronomes e verbos de primeira pessoa que remetem aos interlocutores do texto. Exemplos: "Mesmo vivendo numa época denominada 'era da informação', a qual possibilita acesso rápido à leitura de uma gama imensurável de informações, convivemos com o índice...” (PARANÁ, 2009, p. 48);

- Formas verbais no tempo presente, pretérito perfeito do indicativo: "Isso implica dizer que os homens..." (p. 49).

ii) do domínio do discurso teórico:

- Organizadores com valor lógico-argumentativo. Exemplos: “... uma vez que na escola ele não leria e produziria apenas textos escolares, didatizados, mas teria contato com textos presentes nos diversos espaços de socialização que frequenta" (p. 53);

- Presença do auxiliar de modo 'poder': “Contudo, a escola não pode trabalhar só com a norma culta...” (p. 53).

- Procedimento de referência intextextual: “... de acordo com Soares (1998)...” (p. 50); “Na visão de Bakhtin (1992, p. 354) ...” (p. 51); "Para Candido (1972)..." (p. 57).

- Verbos na forma do presente. Exemplos: "revelam"; "assumem"; "requer"; "visa aprimorar"; "implica"; "precisa" (p. 48-62). 
Portanto, nas cartas há predominância de discurso interativo, o que, segundo Bronckart e Machado (2004), demonstra a subjetividade das secretárias e de seus posicionamentos diante do que enunciam. Elas construíram, acreditaram e se orgulham do documento, conforme expressões explicitadas no texto. Ou seja, existe conjunção entre o tema tratado e o mundo das agentes produtoras. $\mathrm{E}$ ainda estabelecem uma forte proximidade com os destinatários ao fazerem uso de recursos como os pronomes de primeira pessoa e pronomes que se dirigem diretamente aos destinatários. Ou seja, as agentes produtoras interagem com os destinatários de forma direta.

Já na primeira seção, que relata os fatos históricos, expõe-se uma objetividade no trato com o assunto tratado. Depois, no restante do texto, a presença do discurso interativo estabelece proximidade entre os produtores do documento e seus destinatários, proximidade que se revela também na temporalidade, o envolvimento dos interlocutores se faz agora, nesse momento, momento de mudanças, de comprometimento, de envolvimento de todos para o sucesso da diretriz. O tema tratado é conjunto ao mundo do agente produtor e este interage com os destinatários de forma direta. Contudo, como se pretende também uma objetividade e aceitação dos preceitos teórico-metodológicos do documento como verdades a serem seguidas, o discurso teórico se fusiona no interativo e por isso em vários segmentos do texto não existem referências ao agente produtor, o tema passa a ser exposto de forma autônoma.

A forma que a sequencialidade configura a DCE-LP confirma estas interpretações, não há predominância de uma sequência sobre a outra na relação das partes que compõem o documento. Isto é, reconhecendo que o documento pode ser de difícil compreensão por seus destinatários, a carta da secretária da educação apresenta mais a sequência explicativa, com a construção de algumas poucas sequências argumentativas para apresentação do ponto de vista da autora a respeito de como era a prática educativa e da formação continuada antes dela assumir a secretaria e a respeito da solução aos problemas: a construção das DCEs.

Não muito diferente estrutura-se a carta da chefe do DEB, há a descrição do que compõem o caderno em questão (a DCE-LP), de como o documento foi elaborado e produzido, exemplo: "Assim, os textos que compõem este caderno se apresentam na seguinte ordem e estrutura: $\mathrm{O}$ primeiro, sobre..." (p. 6); com a presença de explicação das expectativas a respeito do documento frente ao trabalho pedagógico do professor. 
Nas demais partes da DCE-LP, uma das sequências que se sobressai é a injuntiva, o que caracteriza o documento como prescritivo, evidentemente, pelo objetivo de fazer com que os professores encaminhem suas práticas pedagógicas de forma condizente com as concepções teórico-metodológicas da SEED. Recortamos exemplos de diferentes partes do texto da utilização de verbos no infinitivo configurando a sequência injuntiva: "O professor de Língua Portuguesa precisa, então, propiciar ao educando a prática, a discussão, a leitura de textos das diferentes esferas sociais (jornalística, literária, publicitária, digital, etc)" (p. 50); "No caso da leitura de textos poéticos, o professor deve estimular, nos alunos, a sensibilidade estética, fazendo uso, ..." (p. 76).

Também há presença de sequências explicativas, as quais, segundo Machado e Bronckart (2009), demonstram à necessidade da SEED fazer com que os seus interlocutores aprofundem seus conhecimentos a respeito das premissas defendidas pela secretaria, ou seja, a SEED reconhece que o conteúdo temático pode ser de difícil compreensão para os professores, por isso constrói o texto com várias sequências explicativas. No mesmo sentido, busca descrever alguns pormenores sobre o tema tratado, o que faz por meio das sequências descritivas. Por fim a presença de sequências argumentativas, porque o tema é considerado controverso pelo agente produtor, o que pode causar posicionamentos dos professores diferentes dos prescritos na DCE-LP. Assim, apresentam-se argumentos, buscando convencer os professores sobre "a verdade das proposições teóricas e metodológicas neles veiculadas” (MACHADO; BRONCKART, 2009, p. 55).

Para uma visualização mais geral, apresentamos a seguir um quadro-síntese expondo o que foi analisado, de forma a tornar mais clara a apresentação das principais características acima listadas sobre o contexto de produção e sobre o nível organizacional da DCE-LP: 
Quadro 1 - Elementos que compõem o contexto de produção e o nível organizacional da DCE-LP

\begin{tabular}{|l|l|}
\hline $\begin{array}{l}\text { Principais actantes } \\
\text { postos em cena }\end{array}$ & $\begin{array}{l}\text { A SEED, principal agente-produtora, e os } \\
\text { professores da Educação Básica, principais } \\
\text { destinatários da prescrição. }\end{array}$ \\
\hline $\begin{array}{l}\text { Momento em que o } \\
\text { texto foi produzido }\end{array}$ & $\begin{array}{l}\text { Inicio da elaboração em 2004, publicação da } \\
\text { versão final em 2009. }\end{array}$ \\
\hline Tipos de discursos & $\begin{array}{l}\text { Presença do discurso interativo, do relato } \\
\text { interativo e do discurso interativo-teórico } \\
\text { fusionado marcando a aproximação interativa } \\
\text { de forma direta entre o agente produtor e os } \\
\text { destinatários do documento. }\end{array}$ \\
\hline Sequencialidade & $\begin{array}{l}\text { Presença de sequências explicativas, descritivas, } \\
\text { argumentativas, mas com a predominância da } \\
\text { sequência injuntiva caracterizando o documento } \\
\text { como prescritivo. }\end{array}$ \\
\hline
\end{tabular}

\section{$2.2 \mathrm{O}$ nível enunciativo}

O nível enunciativo da DCE-LP revela, por meio das marcas de pessoa, a representação do enunciador no agir representado como aquele que age coletivamente. A primeira pessoa do plural está presente em todo o texto, carta e DCE-LP: assumimos, pretendemos, disponibilizamos, etc. Essa coletividade é corroborada ainda pelo imbricamento de vozes presentes no texto, o que promove um caráter de ocultamento sobre quem é o responsável pela prescrição. Estão presentes as vozes: da SEED, enunciador institucionalizado, descrito logo na capa do documento, portanto, o autor empírico da produção; da secretária da educação e a chefe do DEB, as quais assinam as circulares administrativas e por representarem a secretaria podem também ser consideradas autoras empíricas; das autoridades que validam o documento, descritas na folha de rosto do documento, algumas delas podendo ser consideradas "vozes sociais", por procederem de outras instituições sociais mencionadas como instâncias externas de avaliação do conteúdo apresentado (BRONCKART, 2009), como, por exemplo, os leitores críticos da disciplina de LP e da área pedagógica educacional, também descritos na folha de rosto. 
É possível também identificar a voz do próprio documento, isto é, a obscuridade sobre o enunciador responsável pela prescrição é tão complexa que o próprio documento é apresentado como um ser animado, sujeito das ações. Exemplos: "as Diretrizes Curriculares Estaduais de Lingua Portuguesa requerem, neste momento histórico, novos posicionamentos em relação às práticas de ensino" (PARANÁ, 2009, p. 48); “As Diretrizes ora propostas assumem uma concepção de linguagem que não se fecha 'na sua condição de sistema de formas'...” (p.50); "Na prática da oralidade, estas Diretrizes reconhecem as variantes linguísticas...” (p. 65). Nesses exemplos, e ainda em mais três ocorrências, a DCE-LP requer, assume, reconhece, fundamenta e até mesmo recomenda que os professores ajam de uma forma ou de outra.

Apresentam-se também as vozes de diversos especialistas/estudiosos da área de educação e de língua portuguesa com a intenção de dar mais autoridade e cientificidade ao discurso teórico proferido. Entre eles estão: Irlandé Antunes, Michael Bakhtin/Volochinov, Beth Brait, Antônio Cândido, Demerval Saviani, Magda Soares, entre outros. Vozes essas que, na maioria das vezes são apresentadas pela utilização de aspas, em citação direta, e em outras no uso de paráfrases.

Os Modalizadores - como um documento que pretende instruir os envolvidos no ensino da LP para encaminhamentos condizentes ao que pretende a SEED, os modalizadores mais presentes são deônticos, marcando os que os interlocutores do documento devem fazer, o que a eles são permitido e o que é obrigatório. Exemplos: deverá; precisam; é importante; é necessário; é imprescindível; entre outros.

No caso dos modalizadores epistêmicos que marcam a certeza, o saber, a crença que se tem sobre o conteúdo temático, eles estão presentes na DCE-LP em poucas ocorrências se comparados aos deônticos. O mais presente é o "pode" que marca, na maioria das vezes, o domínio da possibilidade. Alguns exemplos: "ao narrar um fato (real ou fictício), o professor poderá abordar a estrutura da narrativa...” (p. 67); “O professor pode propor questões abertas, discussões...” (p. 82).

Portanto, a predominância de modalizadores deônticos, sendo o presente o "deve" e o "é preciso que/precisa" institui a ordem, a obrigatoriedade de alguém para envolver-se em uma situação, em um procedimento. O que é bastante coerente com a função dos mecanismos 
enunciativos que se relacionam mais diretamente "ao tipo de interação que se estabelece entre o agente produtor e seus destinatários” (BRONCKART, 2009, p. 120). Ou seja, o agente-produtor, ao buscar instruir seus destinatários para aquilo que devem fazer, utiliza recursos linguísticos que explicitam sua pretensão. Nesse sentido, a construção do texto com a utilização de modalizadores deôticos, segundo Machado e Bronckart (2009), fundamenta a relação de hierarquia que se pretende construir sobre a instância enunciativa em posição superior à posição dos destinatários. Exemplos de modalizadores relacionados aos interlocutores do documento: “O professor de Língua Portuguesa precisa, então, propiciar ao educando a prática, a discussão, a leitura de textos..." (p. 50); “O educador deve atentar-se, também, aos textos não-verbais,...” (p. 72); “O professor precisa tomar conhecimento da realidade sócio-cultural dos educandos...” (p. 74).

Em uma padronização, apresentamos um quadro-síntese com as principais características listadas a respeito do nível enunciativo da DCE-LP: 
Quadro 2 - Elementos que compõem o nível enunciativo da DCE-LP

\begin{tabular}{|l|l|}
\hline $\begin{array}{l}\text { Marcas de pessoa na } \\
\text { responsabilização } \\
\text { enunciativa }\end{array}$ & $\begin{array}{l}\text { Predomínio da } 1^{\text {a }} \text { pessoa do plural revelando a } \\
\text { representação do enunciador no agir } \\
\text { representado como aquele que age } \\
\text { coletivamente. }\end{array}$ \\
\hline $\begin{array}{l}\text { Marcas de inserção } \\
\text { de vozes na } \\
\text { responsabilização } \\
\text { enunciativa }\end{array}$ & $\begin{array}{l}\text { Imbricamente de vozes (da SEED, da secretária } \\
\text { da educação e da chefe do DEB, das } \\
\text { autoridades e dos leitores críticos que validam o } \\
\text { documento) corroborando o agir coletivo, o que } \\
\text { promove um ocultamento sobre quem é o } \\
\text { responsável pela prescrição. O próprio } \\
\text { documento, a Diretriz, é apresentado como um } \\
\text { ser animado reforçando a obscuridade sobre o } \\
\text { enunciador responsável pela prescrição, a } \\
\text { SEED. } \\
\text { Vozes de especialistas/estudiosos da área de } \\
\text { educação e de língua portuguesa explicitando a } \\
\text { autoridade e cientificidade do discurso teórico } \\
\text { proferido no documento. }\end{array}$ \\
\hline $\begin{array}{l}\text { Predominância de modalizadores deônticos, o } \\
\text { que fundamenta a relação de hierarquia sobre a } \\
\text { instância enunciativa, a SEED em posição } \\
\text { superior aos destinatários, os professores da } \\
\text { Educação Básica; marcam textualmente a } \\
\text { obrigatoriedade dos professores cumprirem o } \\
\text { estabelecido pela SEED. }\end{array}$ \\
\hline Modalizadores
\end{tabular}

\subsection{O nível semântico}

O principal actante posto em cena pelo documento é o professor. Para apreender o papel semântico-sintático que ele desempenha nos enunciados da DCE-LP, pautamo-nos nas classificações de Fillmore (1975, apud Bronckart e Machado, 2004), para quem os papéis sintático-semânticos que podem ser atribuídos aos protagonistas postos em cena em um texto, segundo classificação de Fillmore, são: 
- Agentivo, o ser animado responsável por um processo dinâmico $[\ldots]$.

- Instrumental, o ser inanimado que é a causa imediata de um evento ou que contribui para a realização de um processo dinâmico [...].

- Atributivo (ou Experenciador), a entidade a quem é atribuído uma determinada sensação ou um determinado estado [...].

- Objetivo, a entidade que sofre um processo dinâmico [...].

- Beneficiário, o destinatário animado de um processo dinâmico [...].

- Factivo, que indica o estado ou o resultado final de uma ação [...]. (BRONCKART; MACHADO, 2004, p. 152).

O resultado das análises aponta que o professor tem, em quase 100\% das orações, a função sintática de sujeito e a função semântica agentiva, ou seja, o professor é responsável pelo processo, contudo não no sentido de ser o ator, mas sim responsável em seguir, em cumprir as orientações da DCE-LP. Exemplo: "No caso da leitura de textos poéticos, o professor deve estimular, nos alunos, a sensibilidade estética, fazendo uso, para isso, de um instrumento imprescindível e, sem dúvida, eficaz: a leitura expressiva" (PARANÁ, 2009, p. 76). Sendo assim, ele é apenas o agente "de um processo que é colocado como tendo um caráter inelutável, quase que mecânico. Seu trabalho maior é representado como sendo o de aplicar os princípios, os conteúdos e metodologias prescritas" (MACHADO et al., 2009, p. 25). Também porque a ele não são atribuídos motivos ou razões para agir, nem intenções ou um querer-fazer, e nem tão pouco capacidades próprias. $\mathrm{O}$ plano motivacional tem caráter externo ao professor e de ordem institucional, uma vez que são determinadas pelo documento. A intencionalidade também é estabelecida pelo documento e refere-se a um agir coletivo.

Vale destacar que nas duas cartas, o professor chega a ser apresentado como um ator, pois recebe agradecimentos e o reconhecimento de sua participação na construção do documento. Contudo, em todo o texto da DCE-LP propriamente dita, o seu papel é de executor do prescrito pela SEED.

Outro aspecto sobre a DCE-LP como texto prescritivo é a característica de apresentar um contrato de sucesso. De acordo com Adam (2001), os textos prescritivos têm mesmo como característica apresentar um "contrato implícito de verdade e de promessa de sucesso [que] garante ao destinatário que, se agir conforme todas as recomendações e se respeitar 
os procedimentos que lhe são indicados, ele atingirá os objetivos visados" (p. 21-23). Exemplo do contrato de sucesso travado pela DCE-LP:

A leitura dessas múltiplas linguagens, realizada com propriedade, garante o envolvimento do sujeito com as práticas discursivas, alterando 'seu estado ou condição em aspectos sociais, psíquicos, culturais, políticos, cognitivos, linguísticos e até mesmo econômicos'. (PARANÁ, 2009, p. 51- grifo meu).

E mais, há ainda a exposição de agravante, de castigo, do não alcance do sucesso, caso o professor não cumpra o prescrito:

É tarefa da escola possibilitar que seus alunos participem de diferentes práticas sociais que utilizem a leitura, a escrita e a oralidade, com a finalidade de inseri-los nas diversas esferas de interação. Se a escola desconsiderar esse papel, o sujeito ficará a margem dos novos letramentos, não conseguindo se constituir no âmbito de uma sociedade letrada. (p. 48).

A responsabilidade do sucesso ou do fracasso é, então, atribuída à escola, no nível do professor, coordenador, pedagogo, mas segundo Machado et al. (2009) as reais detentoras do controle geral são as chefias: a SEED, no caso. Seriam do professor se as instituições superiores na hierarquia realmente dessem à escola responsabilidades reais e meios para exercê-las (MACHADO et al., 2009).

Pela última citação, fica aparente também a presença de outro actante na DCE-LP, o aluno, o qual, conforme Paveau (1999 apud MACHADO; BRONCKART, 2005), está sempre presente nos textos prescritivos, junto ao produtor do discurso e ao agente do agir prescritivo, e é denominado como o beneficiário desse agir. Outros exemplos da presença do aluno como beneficiário do agir do professor:

$\mathrm{Na}$ sala de aula e nos outros espaços de encontro com os alunos, os professores de Língua Portuguesa e Literatura têm o papel de promover o amadurecimento do domínio discursivo da oralidade, da leitura e da escrita, para que os estudantes compreendam e possam interferir nas relações de poder com seus próprios pontos de vista, 
fazendo deslizar o signo-verdade-poder em direção a outras significações que permitam, aos mesmos estudantes, a sua emancipação e a autonomia [...] (p. 64).

É por meio do aprimoramento linguístico que o aluno será capaz de transitar pelas diferentes esferas sociais, usando adequadamente a linguagem tanto em suas relações cotidianas quanto nas relações mais complexas. (p. 67).

Sobre o plano dos recursos para o agir, especificamente, as capacidades, ou seja, processos mentais, atitudes, sentimentos, valores, conhecimentos teóricos e práticos, processos físicos, entre outros, imprescindíveis para a realização do agir, o documento dá uma falsa impressão de que elas são atribuídas ao professor, o que atribuiria a ele o papel de ator. Por exemplo,

... o professor pode planejar e desenvolver um trabalho com a oralidade que, gradativamente, permita ao aluno conhecer, usar também a variedade linguística padrão e entender a necessidade desse uso em determinados contextos sociais. (p. 66).

A utilização do verbo "pode", neste e em muitos outros trechos, marcaria possibilidades de ações designada ao professor, isto é, atitudes que poderiam partir do professor conforme seu julgamento, porém, podem ser substituídos completamente pelo verbo "dever", uma vez que, ainda utilizando o trecho em citação como exemplo de nossa assertiva, caso o professor não planeje e desenvolva o trabalho com a variedade linguística padrão, o aluno não terá aprimoramento linguístico para participar de diferentes esferas. Para corroborar essa nossa interpretação, cito ainda determinações prescritas no documento a respeito do trabalho com as práticas de linguagem:

É na escola que o aluno, e mais especificamente o da escola pública, deveria encontrar o espaço para as práticas de linguagem que possibilitem interagir na sociedade, nas mais diferentes circunstâncias de uso da língua, em instância públicas ou privadas. (p. 38). 
Se o trabalho com a língua deve considerar as práticas linguísticas que o aluno traz ao ingressar na escola, é preciso que, a partir disso, seja trabalhada a inclusão dos saberes necessários ao uso da norma padrão e acesso aos conhecimentos para os multiletramentos, a fim de constituírem ferramentas básicas no aprimoramento da aptidões linguísticas dos estudantes. (p. 48).

Imprescindível destacarmos dessa última citação a utilização da locução verbal "é preciso" confirmando que o "pode" de nosso primeiro exemplo, sustenta-se como um "deve/é preciso".

A falsa impressão se constrói também pelo fato de o documento trazer possibilidades de atividades que podem ser desenvolvidas pelo professor nas salas de aula por meio de um Anexo. Possibilidades, sugestões que para Souza (2010) se configuram como listas de conteúdos como subsídio aos professores.

O quadro-síntese a seguir permite a visualização da principal característica acima listada sobre o nível semântico da DCE-LP:

Quadro 3 - Elementos que compõem o nível semântico da DCE-LP

\begin{tabular}{|l|l|}
\hline O professor & Função sintática de sujeito e a função semântica \\
& agentiva - mas não é apresentado como ator, é \\
& apenas o responsável em cumprir as orientações \\
da DCE-LP. & \\
& É agente no sentido de aplicador dos princípios, \\
& dos conteúdos e das metodologias prescritas. \\
& A ele não são atribuídos motivos ou razões para \\
& agir, nem intenções ou um querer-fazer, e nem \\
& tão pouco capacidades próprias. \\
\hline O aluno & É o beneficiário do agir do professor. \\
\hline
\end{tabular}

\section{Considerações Finais}

Interessadas em compreender qual a representação que as instâncias responsáveis pelo sistema educacional do estado do Paraná têm do professor que age na educação básica neste estado, e, sobretudo, se o prescrito relacionase com a definição apresentada do professor como um sujeito epistêmico, 
analisamos toda a rede discursiva estabelecida na DCE-LP. Os resultados demonstram que os envolvidos no sistema de ensino colocados em cena pela DCE-LP são: a SEED, como principal agente-produtora do documento; os destinatários, de um modo geral; o próprio documento, em momentos de personificação do ser inanimado; os alunos, beneficiários do agir do professor, e o professor da educação básica, principal destinatário e actante colocado em cena, que é quem recebe a representação social de agente, simples participante de um processo sobre o qual não lhe são atribuídas responsabilidades para seu agir sobre sistema educacional do estado do Paraná, cabendo-lhe apenas seguir o prescrito pelo documento, o que entra em conflito com a definição a ele estabelecida.

\section{Referências}

ABREU-TARDELLI, L. A. trabalhodoprofesson@chateducacional.com.br: aportes para compreender o trabalho do professor iniciante em EAD. 2006. Tese (Doutorado em Linguística Aplicada e Estudos da Linguagem) - Pontifícia Universidade Católica de São Paulo, São Paulo. 2006.

ADAM, J. M. Entre Conseil et consigne: les genres de L'Incitation à L'Action. Pratiques, Metz/France, n. 111/112, p. 7-38, Déc. 2001.

AMIGUES, R. Trabalho do professor e trabalho de ensino. In: MACHADO, A. R. (Org.). O ensino como trabalho: uma abordagem discursiva. Londrina: Eduel, 2004. p. 35-53.

BALTAR, M. O. Letramento radiofônico na escola. Linguagem em (Dis)curso, Tubarão, v. 8, n. 3, p. 563-580, set./dez. 2008.

BRONCKART, J. P. Atividade de linguagem, discurso e desenvolvimento humano. Tradução Anna Rachel Machado, Maria de Lourdes Meirelles Matencio. Campinas: Mercado das Letras: 2006.

BRONCKART, J. P. O agir nos discursos: das concepções teóricas às concepções dos trabalhadores. Tradução Anna Rachel Machado e Maria de Lourdes Meirelles Matencio. Campinas: Mercado de Letras, 2008. 
BRONCKART, J. P. Atividade de linguagem, textos e discurso: por um interacionismo sociodiscursivo. 2. ed. Tradução Anna Rachel Machado e Péricles Cunha. São Paulo: EDUC, 2009 [1999].

BRONCKART, J. P.; MACHADO, A. R. Procedimentos de análise de textos sobre o trabalho educacional. In: MACHADO, A. R. (Org.). O ensino como trabalho: uma abordagem discursiva. Londrina: Eduel, 2004. p. 131-163.

BULEA, E. Linguagem e efeitos desenvolvimentais da interpretação da atividade. Campinas: Mercado das Letras, 2010.

LOUSADA, E. G. A emergência da voz do métier em textos sobre o trabalho do professor. In: MACHADO, A. R.; LOUSADA, E. G.; FERREIRA, A. D. (Orgs.). O professor e seu trabalbo: a linguagem revelando práticas docentes. Campinas: Mercado de Letras, 2011. p. 61-96.

MACHADO, A. R.; BRONCKART, J. P. De que modo os textos oficiais prescrevem o trabalho do professor? Análise comparativa de documentos brasileiros e genebrinos. Delta, São Paulo, v. 21, n. 2, July/ Dec. 2005.

MACHADO, A. R.; BRONCKART, J. P. (Re-)configurações do trabalho do professor construídas nos e pelos textos: a perspectiva metodológica do grupo ALTER-LAEL. In: MACHADO, A. R. Linguagem e educação: o trabalho do professor em uma nova perspectiva. Organização Vera Lúcia Lopes Cristóvão e Lilia Santos Abreu-Tardelli. Campinas: Mercado de Letras, 2009. p. 31-77.

MACHADO, A. R. et al. Relações entre linguagem e trabalho educacional: novas perspectivas e métodos no quadro do Interacionismo Sociodiscurdivo. In: MACHADO, A. R. Linguagem e educação: o trabalho do professor em uma nova perspectiva. Organização de Vera Lúcia Lopes Cristóvão e Lilia Santos Abreu-Tardelli. Campinas: Mercado de Letras, 2009. p. 15-29.

PARANÁ. Secretaria de Estado da Educação. Diretrizes Curriculares de Lingua Portuguesa para os anos finais do Ensino Fundamental e Ensino Médio. Curitiba: SEED, 2009. 
VYGOTSKY, L. S. A construção do pensamento e da linguagem. São Paulo: Martins Fontes, 2000.

VYGOTSKY, L. S. A formação social da mente: o desenvolvimento dos processos psicológicos superiores. 7. ed. Organizadores Michael Cole et al. Tradução José Cipolla Neto, Luís Silveira Menna Barreto, Solange Castro Afeche. São Paulo: Martins Fontes, 2007. 